Int. J. Adv. Eng. Pure Sci. 2020, I: 68-72

DOI: 10.7240/jeps.6II85।

RESEARCH ARTICLE / ARAŞTIRMA MAKALESI

\title{
Hipogonadotropik Hipogonadizm ve Kallmann Sendromunda Yeni Tanımlanan DCC/NTN1 Mutasyonları
}

\author{
Novel DCC/NTN1 Mutations in Patients with Hypogonadotropic Hypogonadism/Kallmann \\ Syndrome
}

\author{
Leman Damla KOTAN 1 (D), Semine ÖZDEMIR DILEK 1 (D), Gamze AKKUŞ ${ }^{2}$ (D), İhsan TURAN 3 (iD), \\ Bilgin YÜKSEL ${ }^{1}$ (D) , Ali Kemal TOPALOĞLU 4 (iD \\ ${ }^{1}$ Çukurova Üniversitesi, Tıp Fakültesi, Çocuk Endokrinolojisi Bilim Dall, 01330, Adana, Türkiye \\ ${ }^{2}$ Hatay Devlet Hastanesi, Endokrinoloji Bölümü, Hatay, Türkiye \\ ${ }^{3}$ Şanlıurfa Eğitim ve Araştırma Hastanesi, Çocuk Endokrinoloji Kliniği, Şanlıurfa, Türkiye \\ ${ }^{4}$ Mississippi Üniversitesi Tip Merkezi, Pediatri Bölümü ve Nörobiyoloji ve Anatomik Bilimler Bölümü, Mississippi, ABD
}

$\ddot{O} \mathbf{z}$

Embriyonik gelişim sırasında gonadotropin salgılatıcı hormon (Gonadotropin Releasing Hormone, GnRH) nöronları, koku alma nöronlarının akson rehberliğini kullanarak, oluştukları olfaktör plakoddan son hedefleri olan hipotalamusa göç etmektedirler. Bu rehberlikte meydana gelen kusur nedeniyle nöronların yanlış yönlendirilmesi bozulmuş koku fonksiyonu ve Hipogonadotropik Hipogonadizm (HH) birlikteliğindeki Kallmann Sendromu (KS) ile sonuçlanmaktadır. Netrin-1 ve reseptörü DCC (Deleted in Colorectal Cancer) sinyalizasyonu, GnRH migrasyonu için bir yapı iskelesi görevi gören olfaktör liflerin gelişiminde görev almaktadır. Yakın dönemde, DCC/NTN1 mutasyonlarının GnRH nöron göçünde ve HH/KS hastalık etiyolojisinde rol oynadığı ilk kez gösterilmiştir. Çalışmamızda, HH ve KS hastalarında $D C C / N T N 1$ genlerindeki olası patojenik varyantların tanımlanması amaçlanmıştır. Bu doğrultuda, $D C C$ geninde daha önce bildirilmemiş iki varyant (p.Arg386Gln, p.Arg1124Cys) ve bir mutasyon (p.Gly470Asp), NTN1 geninde ise daha önce bildirilmemiş bir varyant (p.Pro73Ser) heterozigot şekilde toplamda beş hastada tespit edilmiştir. Ayrıca üç hastanın HH-ilişkili diğer genlerde (OTUD4, SEMA3A, CHD7 ve WDR11) nadir sekans varyantı taşıdığı belirlenmiştir. Sonuç olarak, DCC ve NTN1 genlerindeki üç nadir sekans varyantının HH/ KS hastalık modeliyle ilişkili olduğu ilk kez tanımlanmıştır. Olası patojenik varyantları hastalığın her iki formunda da gözlememiz, anosmik ve normosmik model arasında net bir ayrım olmadığını bir kez daha doğrulamıştır.

Anahtar Kelimeler: akson rehberliği, Kallmann sendromu, hipogonadotropik hipogonadizm, oligogenik kalıtım, DCC, NTN1

\begin{abstract}
During embryonic development, Gonadotropin Releasing Hormone (GnRH) neurons migrate from the olfactory placode to their final target hypothalamus, using axon guidance of olfactory neurons. Misdirection of neurons due to a defect in this guidance results in Kallmann Syndrome (KS) associated with impaired olfactory function and Hypogonadotropic Hypogonadism (HH). The signaling of Netrin-1 and its receptor DCC (Deleted in Colorectal Cancer) is involved in the development of olfactory fibres which act as a scaffold for migration. Recently, DCC/NTN1 mutations have been shown to play a role in GnRH neuron migration and disease ethiology. In our study, we aimed to identify possible pathogenic variants in DCC/NTN1 genes in HH and KS patients. Accordingly, two novel (p.Arg386Gln, and p.Arg$1124 \mathrm{Cys}$ ) and one previously reported (p.Gly470Asp) rare sequence variants in DCC and another novel rare sequence variant (p.Pro73Ser) in NTN1 were identified in five patients in the heterozygous state. In addition, three of the patients had RSVs in other HH-related genes (OTUD4, SEMA3A, CHD7, and WDR11). In conclusion, likely causative RSVs in DCC/NTN1 have been identified for the first time to be associated with $\mathrm{HH} / \mathrm{KS}$ disease model. Our observation of the variants in both forms of the disease confirmed once again that there was no clear discrimination between the anosmic and normosmic forms.
\end{abstract}


Keywords: axon guidance, Kallmann Syndrome, hypogonadotropic hypogonadism, oligogenic inheritance, DCC, NTN1

\section{GİRIŞ}

Koku alma duyusundaki yetersizliğin Hipogonadotropik Hipogonadizm (HH) ile birlikteliği klinik olarak Kallmann Sendromu (KS [MIM 308700, 147950, 244200, 610628, $612370,612702])$ olarak tanımlanmaktadır [1]. Embriyonik gelişim sırasında olfaktör plakodda oluşan gonadotropin salgilatic hormon (Gonadotropin Releasing Hormone, GnRH) nöronları, son hedefleri olan hipotalamusa ulaşmak için koku alma nöronlarının akson rehberliğini kullanmaktadırlar. Dolayısıyla KS hastalarında bu rehberlikte oluşan bozukluğun, GnRH nöronlarının yanlış yönlendirilmesine neden olduğu ileri sürülmektedir [2, 3]. Bugüne kadar, bu nörogelişimsel süreci kontrol eden çok sayıda faktör tanımlanmış ve aksonal kılavuzlu göç yolunda 30'dan fazla gende nedensel mutasyonlar bildirilmiştir [4].

Akson rehberlik yolağında Semafor, Netrin, Slit, İtici Rehberlik Molekülü ve Ephrin olmak üzere beş kanonik protein ailesi tanımlanmıştır [3]. Yolakta yer alan netrin (netrin 1-5), nöronal gelişimde önemli rol oynamaktadır. Akson büyümesine aracılık eden DCC (Deleted in Colorectal Cancer) ise netrin için fonksiyonel bir reseptördür [5, 6]. Kemirgen çalışmalarında Dcc inaktivasyonunun, netrin-1 eksikliği ile uyumlu şekilde aksonal projeksiyon bozukluğuna neden olduğu gösterilmiştir [7]. Bouilly ve ark. 2017 yılında HH hastalarında DCC/NTN1 mutasyonlarının, fare GnRH nöron ontogenezindeki rolleriyle benzer sonuçlara sahip olduğunu raporlamış ve her iki gen oligogenik kalıtım listesine dahil edilmiştir [8].

Çalışmamızda, HH ve KS hastalarında DCC/NTN1 genlerindeki olası patojenik varyantların tanımlanması ve bu hastalarda hastalık ile ilişkili diğer genlerde bulunan nadir gen değişimlerini belirlenmesi amaçlanmıştır. Bu doğrultuda, HH/KS kliniği için hastalık patogenezinde tek başına yeterli olmayan ancak potansiyel olarak zararlı yeni varyantlar oligogenik kalıtıma eklenmiştir.

\section{YÖNTEM}

HH kızlarda 13, erkeklerde 14 yaşında olmasına rağmen düşük bazal gonadotropin seviyeleri ile pübertal gelişimin eksikliği olarak tanımlanmaktadır [9]. KS'li hastalarda koku duyusunun kısmi (hiposmi) veya tam kaybı (anosmi) mevcuttur. Hastaların olfaktör fonksiyon seviyeleri fizik muayene ile belirlenmiştir.

Eksom sekanslaması (Whole Exome Sequencing, WES) daha önce bildirilen yönteme göre yapılmıştır [10]. DCC ve NTN1 genlerinin kodlayan eksonları ve yakın komşuluğundaki gen bölgeleri $\mathrm{HH}$ ve KS hastalarında taranmıştır.
Tespit edilen varyantların alelik frekansları gnomAD (the genome aggregation consortium, https:/gnomad.broadinstitute.org/) ve GME (the Greater Middle East variom project, http://igm.ucsd.edu/gme/) veritabanlarında hastaların etnik kökeniyle uyumlu olarak (ENF, European non-Finnish, TP, Turkish Peninsula) kontrol edilmiş ve her iki veritabanında da 0.001 'den az görülmesi durumunda varyant nadir (Rare Sequence Variant, RSV) olarak kabul edilmiştir. Patojenite skorlamas1 CADD (Combined Annotation Dependent Depletion, https://cadd.gs.washington.edu/snv) yazılımı kullanılarak yapılmış ve 20'yi geçen varyantlar zararlı kabul edilmiştir. Belirlenen kriterler dışında kalan varyantlar çalışmaya dahil edilmemiştir. RSV'ler ayrıca ClinVar (https://www.ncbi.nlm.nih.gov/clinvar/) veritabanında taranmıştır. Varyantların protein üzerindeki lokasyonları UniProt veritabanı (https://www.uniprot.org) ile belirlenmiştir. Tüm varyantlar ACMG/AMP (American College of Medical Genetics and Genomics and the Association for Molecular Pathology) kriterleri gereğince VarSome (https://varsome.com) veritabanı üzerinden değerlendirilmiştir [11]. Hastalıkla ilişkili genlerdeki olası patojenik RSV'ler aynı yöntem kullanılarak belirlenmiştir [2].

Çalışmamız, Çukurova Üniversitesi Tıp Fakültesi Etik Kurulu tarafindan onaylanmış (no: 82/47) ve çalışma hastalarından ve/veya velilerinden yazılı onam alınmıştır.

\section{BULGULAR}

Çalışmamızda, DCC (HGNC ID: 2701, NM_005215.3) geninde daha önce tanımlanmamış iki varyant (c.1157G $>$ A, p.Arg386Gln; c.3370C $>$ T, p.Arg1124Cys) ve bir mutasyon (c.1409G>A, p.Gly470Asp), NTN1 (HGNC ID: 8029, NM_004822.2) geninde ise tanımlanmamış bir varyant (c. $217 \mathrm{C}>\mathrm{T}$, p.Pro73Ser) heterozigot şekilde toplamda beş hastada tespit edilmiştir. Tüm varyantların gnomAD alel frekansları 0.001'den küçük olup, hiçbiri GME veritabanında bildirilmemiştir. Sadece p.Gly470Asp mutasyonunun ClinVar veritabanında kayıtlı olduğu belirlenmiştir. ACMG/ AMP değerlendirmesi ile CHD7 dişındaki tüm varyantların "önemi belirsiz" (Variant Uncertain Significance, VUS) kategorisinde olduğu belirlenmiştir. Ayrıca WES taraması ile üç hastanın HH-ilişkili diğer genlerde (OTUD4, NM_001102653.1, c.2909G $>$ C, p.Arg970Thr; SE$M A 3 A$, NM_006080.2, c.1849C $>$ G, p.Arg617Gly; CHD7, NM_017780.3, c.8197G $>$ A, p.Ala2733Thr ve $W D R 11$, NM_018117.11, c.2305A $>$ G, p.Met769Val) RSV taşıdığ1 belirlenmiştir. İki hasta KS, üç hasta ise HH kliniğindeydi. İki hastada birer, bir hastada ise iki ek gen varyantı tespit edildi. Geriye kalan hastalarda farklı gende varyant bulunamadı. Çalışma hastalarının klinik ve genetik detayları sırasıyla Tablo 1 ve 2'de gösterilmiştir. 
Tablo 1. DCC/NTN1 varyantı tespit edilen hastaların klinik ve laboratuvar özellikleri.

\begin{tabular}{|c|c|c|c|c|c|c|c|c|}
\hline Hasta no & Cinsiyet & Yaş* & FSH (mIU/mL) & LH (mIU/mL) & $\begin{array}{c}\text { Estradiol } \\
\text { (ng/dL) }\end{array}$ & Testosteron (ng/dL) & $\begin{array}{c}\text { Olfaktör } \\
\text { fonksiyon }\end{array}$ & $\begin{array}{c}\text { Akrabalık } \\
\text { I }\end{array}$ \\
\hline E & 19.0 & 0.47 & 0.05 & - & 17 & normosmik & var \\
\hline II & K & 14.5 & 0.50 & $<0.02$ & 5.0 & - & normosmik \\
\hline III & E & 15.8 & 2.80 & 0.36 & - & 24 & yok \\
\hline IV & E & 27.0 & 0.60 & 0.42 & - & 38 & hormosmik & yok \\
\hline V & E & 17.5 & 0.84 & 0.21 & - & $1660^{+}$ & hiposmik & var \\
\hline
\end{tabular}

E, erkek; K, kadın; - , belirlenmemiş; *tanı yaşı; ${ }^{+}$tedavi altında

Tablo 2. Tanımlanan heterozigot $D C C / N T N 1$ varyantlarının moleküler genetik özellikleri.

\begin{tabular}{|c|c|c|c|c|c|c|c|c|c|}
\hline $\begin{array}{c}\text { Hasta } \\
\text { no }\end{array}$ & Gen & $\begin{array}{l}\text { cDNA, } \\
\text { Protein }\end{array}$ & $\begin{array}{c}\text { gnomAD } \\
\text { ENF }\end{array}$ & $\begin{array}{c}\text { GME } \\
\text { TP }\end{array}$ & $\begin{array}{l}\text { Protein do- } \\
\text { maini }\end{array}$ & $\begin{array}{l}\text { CADD } \\
\text { skoru }\end{array}$ & dbSNP & $\begin{array}{c}\text { Ek gen var- } \\
\text { yantı/ } \\
\text { Zigosite } \\
\end{array}$ & $\begin{array}{c}\text { Ek gen var- } \\
\text { yantı CADD } \\
\text { skoru } \\
\end{array}$ \\
\hline I & $D C C$ & $\begin{array}{l}\text { c.1409G }>\text { A, } \\
\text { p.Gly470Asp }\end{array}$ & 0.005069 & - & $\begin{array}{l}\text { Fibronectin ty- } \\
\text { pe-III } 1\end{array}$ & 27.7 & rs141813053 & $\begin{array}{c}\text { OTUD4 } \\
\text { p.Arg970 } \\
\text { Thr } \\
\text { Heterozigot }\end{array}$ & 22.3 \\
\hline II & $D C C$ & $\begin{array}{l}\text { c. } 1409 \mathrm{G}>\mathrm{A}, \\
\text { p.Gly470Asp }\end{array}$ & 0.005069 & - & $\begin{array}{c}\text { Fibronectin ty- } \\
\text { pe-III } 1\end{array}$ & 27.7 & rs141813053 & - & \\
\hline III & $D C C$ & $\begin{array}{l}\text { c. } 1157 \mathrm{G}>\mathrm{A}, \\
\text { p.Arg386Gln }\end{array}$ & 0.0002215 & - & $\begin{array}{l}\text { Ig-like } \mathrm{C} 2- \\
\text { type } 4\end{array}$ & 22.5 & rs140711456 & $\begin{array}{c}\text { SEMA3A } \\
\text { p.Arg617 } \\
\text { Gly } \\
\text { Heterozigot }\end{array}$ & 22.7 \\
\hline IV & $D C C$ & $\begin{array}{c}\text { c. } 3370 \mathrm{C}>\mathrm{T}, \\
\text { p.Arg } 1124 \mathrm{Cys}\end{array}$ & 0.0001027 & - & - & 33.0 & rs547920182 & $\begin{array}{c}\text { CHD7 } \\
\text { p.Ala2733 } \\
\text { Thr } \\
\text { Heterozigot } \\
\text { WDR11 } \\
\text { p.Met769 } \\
\text { Val } \\
\text { Heterozigot }\end{array}$ & $\begin{array}{l}22.4 \\
23.0\end{array}$ \\
\hline V & NTN1 & $\begin{array}{l}\text { c. } 217 \mathrm{C}>\mathrm{T} \text {, } \\
\text { p.Pro73Ser }\end{array}$ & - & - & $\begin{array}{c}\text { Laminin N-ter- } \\
\text { minal }\end{array}$ & 23.0 & - & - & \\
\hline
\end{tabular}

\section{TARTIŞMA}

Kallmann sendromu, GnRH ve olfaktör nöronlarının ortak gelişimindeki bozukluktan kaynaklanmaktadır ve genetik olarak heterojendir [12]. Hastalıkla ilişkili olarak tanımlanan nörogelişimsel genler, ilgili nöronlar arasındaki topografik bağlantı nedeniyle KS ile nöroendokrin genler ise koku alma duyusunun etkilenmediği HH formu ile ilişkilendirilmiştir [13]. Ancak her iki hastalık modeli arasında net bir ayrım yapılamadığından, hem anosmik hem de normosmik kliniğe neden olan gen mutasyonları bildirilmiş ve yakın dönemde bu listeye yenileri eklenmiştir [8, 10, 12].
NTN1 ve ana reseptörü olan $D C C$ 'nin embriyonik gelişim sırasında akson rehberliğinde rol aldığı bilinmektedir [14]. Çalışmalar, DCC/Netrin-1 sinyalizasyonunun GnRH nöron migrasyonu için bir yapı iskelesi görevi gören olfaktör liflerin gelişiminde gerekli olduğunu göstermiştir [15]. Yaptığımız çalışmada III numaralı $\mathrm{HH}$ hastasında saptanan her iki RSV'nin de (DCC p.Arg386Gln ve SEMA3A p.Arg617Gly) aksonal rehberlikte görev alan genlerde olduğu belirlenmiştir [13]. Buna rağmen hastanın olfaktör fonksiyonunun normal olması, hastalığın iki formu arasında net ayrım bulunmadığına yeniden işaret etmektedir. Dolayısıyla tespit edilen varyantların hastada aksonal rehberliği 
tamamen değil kısmen bozduğu, buna bağlı olarak bir grup GnRH nöronunun hedefine ulaşabildiği ancak işlevsiz kaldığı ve/veya işlevini yapmak için yeterli sayıda olmadığını yorumu yapılabilmektedir.

Çalışma hastalarında gözlenen varyantların protein üzerindeki lokasyonu incelendiğinde p.Gly470Asp, FN3 (Fibronectin type-III), p.Arg386Gln ise Ig-like (immunoglobulin-like) domaininde bulunmaktadır. Ig domaini protein stabilitesi, FN3 domaini ise DCC/Netrin-1 bağlantısını üzerinde etkili alanlardır [14]. Dolayısıyla bu bölgelerde meydana gelen bir değişimin zarar verici olacağı düşünülmektedir. Bu öngörüyle uyumlu olarak RSV'lerin CADD skorları patojeniteyi destekleyici şekilde yüksek bulunmuştur.

Aralarında akrabalık ilişkisi bulunmayan iki hastada (I ve II) daha önce bildirilmiş olan $D C C$ p.Gly470Asp mutasyonu tespit edilmiştir. In vitro çalışmalar, bu değişimin sinyal kaybına neden olduğunu ancak DCC/Netrin-1 bağlanmasında bozulma yaratmadığını göstermiştir [8]. Bununla birlikte yapay DCC mutantlarının Netrin-1 ile normal bağlanmasına rağmen hatalı sinyalizasyonları bildirilmiştir [16]. p.Gly470Asp mutasyonu ClinVar veritabanında (ClinVar ID: 187790) konjenital ayna hareketi (Congenital Mirror Movement, CMM) ile ilişkilendirilmiştir. KS vakalarına yarık damak, sağırlık, ayna hareketleri gibi ek anomalilerin de eşlik edebildiği bilinmektedir [2]. Oysaki hastalığın normosmik formu olan HH'de GnRH nöronları hipotalamustaki nihai hedeflerine ulaşmalarına rağmen işlevsizdir. Dolayısıyla HH vakalarında ek anomali beklenmemektedir [2]. İlgili mutasyonu taşıyan her iki normosmik çalışma hastamızda da bu durumla uyumlu olarak ek konjenital anomali yoktur. Bouilly ve ark. çalışmasında p.Gly470Asp değişimine sahip üç KS hastasından sadece birinde ayna hareketi gözlenmiştir [8]. Buna bağlı olarak hastada ek anomalinin ortaya çımasında mutasyonun tek başına değil yardımcı varyantlarla birlikte etkili olduğunu düşünmekteyiz.

Çalışmamızda Mendel dışı kalıtım paterninin bir işareti olarak üç hastanın birden fazla gende RSV taşıdığını tespit ettik [17]. Geleneksel olmayan kalıtım modellerinden biri olan oligogenik kalıtım, belirgin şekilde artan rapor sayısı ile HH hastalık modelinde giderek ön plana çıkmıştır [9, 10, 12]. Hastalıkla ilişkili genlerde gözlenen ancak mevcut bilgilerde klinik yansıması henüz netleşmemiş RSV'lerin bu kalıtım modeline katkıda bulunduğu düşünülmektedir. Farklı genlerde tespit edilen mutasyonlar arası muhtemel sinerjik etkinin belirlenmesi, hücresel veya çevresel faktörler tarafindan da modifiye edilebileceği için, tek gen hastalıklarına oranla daha fazla zaman almaktadır [17]. Dolayısıyla bu alanda yapılan çalışmaların artmasının oligogenik bulmacanın kısa sürede tamamlanabilmesi için çok önemli olduğunu düşünüyoruz. Bu sebeple, özellikle hastalık patogenezinin oluşabilmesi için gerekli olan çoklu etkileşimde, henüz sadece tek gen varyantı belirlenmiş hasta verilerinin (II ve V gibi) ileriye yönelik gen keşfinde yol gösterici olabileceğini öngörmekteyiz.

\section{SONUÇ}

Bu çalışmada $D C C$ ve NTN1 genlerindeki üç nadir sekans varyantının HH ve KS hastalık modeliyle ilişkili olduğu ilk kez tanımlanmıştır. Varyantların hastalığın her iki formunda da gözlenmesi, anosmik ve normosmik model arasında net bir ayrımın olmadığını literatürle uyumlu olarak doğrulamıştır. Ayrıca HH ve KS kliniğindeki hastalarda $D C C$ ve/veya NTN1 olası patojenik nadir sekans varyantlarına ek olarak bilinen diğer $\mathrm{HH} / \mathrm{KS}$ genlerinde mutasyonlar tespit edilmesi, oligogenik kalıtımın bir işareti olacağ için hastalıkla ilişkili diğer gen varyantlarının aranması daha iyi bir genetik yönetimi sağlayacaktır.

\section{Teşekkür}

Bu çalışma Çukurova Üniversitesi Bilimsel Araştırma Projeleri No: 11364 ile desteklenmiştir.

\section{KAYNAKLAR}

[1] Topaloglu, A.K. ve Kotan, L.D. (2010). Molecular causes of hypogonadotropic hypogonadism, Curr Opin Obstet Gynecol, 22, 264-270.

[2] Topaloglu, A.K. (2017). Update on the Genetics of Idiopathic Hypogonadotropic Hypogonadism, J Clin Res Pediatr Endocrinol, 9, 113-122.

[3] Van Battum, E.Y., Brignani, S., Pasterkamp, R.J. (2015). Axon guidance proteins in neurological disorders, The Lancet. Neurology, 14, 532-546.

[4] Maione, L., Dwyer, A.A., Francou, B., Guiochon-Mantel, A., Binart, N., Bouligand, J., Young, J. (2018). GENETICS IN ENDOCRINOLOGY: Genetic counseling for congenital hypogonadotropic hypogonadism and Kallmann syndrome: new challenges in the era of oligogenism and next-generation sequencing, Eur $J$ Endocrinol, 178, R55-R80.

[5] Li, W., Lee, J., Vikis, H.G., Lee, S.H., Liu, G., Aurandt, J., Shen, T.L., Fearon, E.R., Guan, J.L., Han, M., Rao, Y., Hong, K., Guan, K.L. (2004). Activation of FAK and Src are receptor-proximal events required for netrin signaling, Nature neuroscience, 7, 1213-1221.

[6] Yaron, A. ve Zheng, B. (2007). Navigating their way to the clinic: emerging roles for axon guidance molecules in neurological disorders and injury, Dev Neurobiol, 67, 1216-1231.

[7] Fazeli, A., Dickinson, S.L., Hermiston, M.L., Tighe, R.V., Steen, R.G., Small, C.G., Stoeckli, E.T., Keino-Masu, K., 
Masu, M., Rayburn, H., Simons, J., Bronson, R.T., Gordon, J.I., Tessier-Lavigne, M., Weinberg, R.A. (1997). Phenotype of mice lacking functional Deleted in colorectal cancer (Dcc) gene, Nature, 386, 796-804.

[8] Bouilly, J., Messina, A., Papadakis, G., Cassatella, D., Xu, C., Acierno, J.S., Tata, B., Sykiotis, G., Santini, S., Sidis, Y., Elowe-Gruau, E., Phan-Hug, F., Hauschild, M., Bouloux, P.M., Quinton, R., Lang-Muritano, M., Favre, L., Marino, L., Giacobini, P., Dwyer, A.A., Niederlander, N.J., Pitteloud, N. (2018). DCC/NTN1 complex mutations in patients with congenital hypogonadotropic hypogonadism impair $\mathrm{GnRH}$ neuron development, Hum Mol Genet, 27, 359-372.

[9] Kotan, L.D., Cooper, C., Darcan, S., Carr, I.M., Ozen, S., Yan, Y., Hamedani, M.K., Gurbuz, F., Mengen, E., Turan, I., Ulubay, A., Akkus, G., Yuksel, B., Topaloglu, A.K., Leygue, E. (2016). Idiopathic Hypogonadotropic Hypogonadism Caused by Inactivating Mutations in SRA1, J Clin Res Pediatr Endocrinol, 8, 125-134.

[10] Kotan, L.D., Isik, E., Turan, I., Mengen, E., Akkus, G., Tastan, M., Gurbuz, F., Yuksel, B., Topaloglu, A.K. (2019). Prevalence and associated phenotypes of PLXNA1 variants in normosmic and anosmic idiopathic hypogonadotropic hypogonadism, Clin Genet, 95, 320-324.

[11] Richards, S., Aziz, N., Bale, S., ve ark. (2015). Standards and guidelines for the interpretation of sequence variants: a joint consensus recommendation of the American College of
Medical Genetics and Genomics and the Association for Molecular Pathology. Genet Med, 17, 405-424.

[12] Turan, I., Hutchins, B.I., Hacihamdioglu, B., Kotan, L.D., Gurbuz, F., Ulubay, A., Mengen, E., Yuksel, B., Wray, S., Topaloglu, A.K. (2017). CCDC141 Mutations in Idiopathic Hypogonadotropic Hypogonadism, J Clin Endocrinol Metab, 102, 1816-1825.

[13] Stamou, M.I. ve Georgopoulos, N.A. (2018). Kallmann syndrome: phenotype and genotype of hypogonadotropic hypogonadism, Metabolism, 86, 124-134.

[14] Finci, L., Zhang, Y., Meijers, R., Wang, J.H. (2015). Signaling mechanism of the netrin-1 receptor DCC in axon guidance, Prog Biophys Mol Biol, 118, 153-160.

[15] Lakhina, V., Marcaccio, C.L., Shao, X., Lush, M.E., Jain, R.A., Fujimoto, E., Bonkowsky, J.L., Granato, M., Raper, J.A. (2012). Netrin/DCC signaling guides olfactory sensory axons to their correct location in the olfactory bulb, $J$ Neurosci, 32, 4440-4456.

[16] Chen, Q., Sun, X., Zhou, X.H., Liu, J.H., Wu, J., Zhang, Y., Wang, J.H. (2013). N-terminal horseshoe conformation of DCC is functionally required for axon guidance and might be shared by other neural receptors, J Cell Sci, 126, 186-195.

[17] Van Heyningen, V. ve Yeyati, P.L. (2004). Mechanisms of non-Mendelian inheritance in genetic disease, Hum Mol Genet, 13 Spec No 2, R225-233. 